\title{
Processo de socialização e promoção da Cultura de Paz na perspectiva de policiais militares
}

\author{
Socialization process and promotion of a Culture of Peace \\ from the perspective of Military Police Officers
}

Letícia de Sousa MOREIRA ${ }^{1}$

Angela Maria Cristina Uchoa de Abreu BRANCO'

\begin{abstract}
Resumo
Conflitos violentos têm protagonizado grandes tragédias em todo o mundo. Isso ocorre porque a sociedade promove práticas culturais onde competição, agressão e violência são toleradas e mesmo incentivadas. A Cultura de Paz está intrinsecamente relacionada à cooperação e à resolução não violenta dos conflitos. Considerando o contexto da Polícia Militar, este estudo objetivou analisar e compreender a complexidade dos conceitos e valores de violência, paz e Cultura de Paz apresentados por policiais militares. A pesquisa qualitativa realizou entrevistas semiestruturadas com seis policiais militares, quatro homens e duas mulheres, e o procedimento de análise seguiu o modelo construtivointerpretativo. Observou-se que os policiais militares têm dificuldades com o tema da Cultura de Paz e em conceituar e admitir a existência de conflitos positivos. Além disso, não se reconhecem como agentes promotores da Paz nos diversos contextos em que atuam, mas a isto se dispõem após refletirem sobre o tema.
\end{abstract}

Palavras-chave: Cultura de paz; Polícia militar; Socialização; Valores Sociais.

\begin{abstract}
Violent conflicts have led to tragedies worldwide. This happens because society promotes cultural practices in which competition, violence, and aggression are tolerated and even encouraged. The Culture of Peace is intrinsically related to cooperation and peaceful conflict resolution. Taking into account the Military Police context, the present study aims at analyzing and understanding the complexity of the concepts and values of violence, peace, and Culture of Peace presented by the officers. The qualitative methodology was used and semi-structured interviews were conducted with six military police officers, four men and two women. The analyses were based on an interpretive-constructivist approach. The participants demonstrated difficulties in conceptualizing a Culture of Peace and admitting the existence of positive conflicts. Moreover, they did not see themselves as peace promoters in the contexts in which they work. However, they envisioned that possibility after reflecting on the topic.
\end{abstract}

Keywords: Culture of peace; Military police; Socialization; Values social.

\footnotetext{
$\checkmark \nabla \nabla$

1 Universidade de Brasília, Instituto de Psicologia, Programa de Pós-Graduação em Processos de Desenvolvimento Humano e Saúde. Campus Universitário Darcy Ribeiro, Instituto Central de Ciências Sul, 70910-900, Brasília, DF, Brasil. Correspondência para/ Correspondence to: L.S. MOREIRA. E-mail: <leticiamoreirapsi@gmail.com>.

Artigo baseado na dissertação de L.S. MOREIRA, intitulada "Cultura de paz, prevenção da violência e socialização na perspectiva de policiais militares". Universidade de Brasília, 2011.
} 
Questões acerca da violência, conflitos e construção da paz têm despertado o interesse de vários pesquisadores das Ciências Humanas e Sociais, e a Psicologia, mais recentemente, vem buscando investigar essas questões (De Rivera, 2009). Na perspectiva da Psicologia Cultural aqui adotada (Valsiner, 2012), o desenvolvimento humano é entendido como um processo de mudanças que ocorrem ao longo das interações entre os indivíduos e os contextos socioculturais nos quais estão inseridos (Branco \& Oliveira, 2012). Na sociedade em geral, ou em contextos específicos como determinados grupos ou instituições, essas interações produzem efeitos muito significativos na geração dos valores e práticas de seus membros. É, assim, no contexto das interações sociais que a pessoa se constrói, pensa e repensa suas ações de maneira a modificar, ou não, suas práticas ao longo da trajetória de vida.

O contexto de uma instituição militar, dessa forma, pode favorecer e/ou dificultar processos de socialização no sentido da construção de uma cultura de paz. Tem, por um lado, a forte presença da hierarquia e da disciplina, o que delimita o campo interacional, mas, por outro, o policial militar trabalha em interação direta com os membros da sociedade, o que amplia esse campo. Sendo assim, a presente investigação teve por objetivo analisar as crenças e reflexões sobre conceitos, valores e práticas de policiais militares com base na perspectiva da Psicologia Cultural, caracterizada por uma abordagem sociocultural construtivista.

\section{Desenvolvimento humano e cultura}

processo dinâmico que ocorre em contextos culturalmente organizados. Já os processos de socialização decorrem das práticas e valores sociais que conduzem as experiências ao longo da vida (Branco, 2006). A consideração da cultura e a importância das interações sociais destacada pela escola histórico-cultural de Vygotsky (1989) têm levado a um paradigma mais amplo e complexo na Psicologia, bem como a uma visão sistêmica de todo o processo de desenvolvimento humano (Rogoff, 2005).
Com base na ideia de que o ser humano está em constante desenvolvimento, Rogoff (2005) define esse processo como a transformação das práticas socioculturais contínuas que se modificam com o envolvimento de indivíduos ao longo do tempo e em sucessivas gerações. Assim, o desenvolvimento humano precisa ser estudado a partir de uma visão sistêmica, contemplando as diversas dimensões pessoais e culturais que interagem no contexto sociocultural.

Os significados culturais são construídos por meio de processos de internalização e externalização, e não são apenas reproduzidos ou transmitidos de uma geração para a outra. A co-construção de significados é um processo dinâmico e ativo que pressupõe transformações constantes, tanto no nível individual quanto no coletivo, e constitui parte essencial da perspectiva cultural (Valsiner, 2007, 2012).

Em seus estudos sobre o papel da cultura, Cole (1992) definiu mediação cultural como o instrumento para analisar os efeitos da cultura sobre o desenvolvimento. Nessa concepção, a cultura não deve ser entendida como um mero contexto externo a influenciar o desenvolvimento humano, podendo ser estudado como uma simples "variável", mas sim como um meio capaz de gerar signos e significados que produzirão o próprio processo de desenvolvimento. Dessa forma, a cultura está na base desse processo de desenvolvimento, ao mesmo tempo em que é por este construída numa relação bidirecional (Valsiner, 2007).

$\mathrm{Na}$ abordagem da Psicologia Cultural, o sujeito é visto como co-construtivo e atuante em seu próprio desenvolvimento e a cultura é vista como fator constitutivo do sujeito. Nesse sentido, o indivíduo não é independente do contexto cultural em que está inserido, mas também não é mero reflexo deste. Ele mantém relativa autonomia em constituição recíproca com o contexto. A ênfase no papel ativo, consciente e intencional do sujeito psicológico está relacionada a uma concepção dinâmica da cultura que engloba tanto a dimensão material, cristalizada nos produtos culturais, como a simbólica, fluida, presente nos processos culturais de significação do mundo e de si mesma (Valsiner, 2012). 
A cultura, portanto, é vista como um sistema aberto, onde o desenvolvimento acontece entre sistemas que se influenciam mutuamente. Por isso, o fenômeno do desenvolvimento exige um estudo sistêmico e multidisciplinar, onde o objeto do estudo seja considerado em uma relação interdependente com o seu ambiente (Rogoff, 2005). Esses conceitos teóricos consolidam, portanto, a ideia de que ações e interações voltadas para a paz podem ser promovidas e dependem tanto dos sujeitos quanto das instituições envolvidas no processo (Moreira \& Branco, 2012).

\section{Paz, Cultura de Paz, conflito e violência como processos culturais}

De acordo com Guimarães (2005), os estudos sobre a paz começam a se libertar do domínio dos estudos militares - ou sobre a guerra -, para ganhar autonomia e abrangência próprias. A problemática da paz em si está sendo circunscrita de forma abrangente, abarcando desde aspectos psicológicos, passando pela organização socioeconômica e política, até atingir o plano cultural. Proliferam os estudos sobre Cultura de Violência/Cultura de Paz estimulados, especialmente, pela Unesco (1991).

Segundo o Ministério da Saúde (Brasil, 2009), a paz é um fenômeno complexo que envolve a construção de relações e estrutura sociais em que existam justiça, igualdade, respeito e liberdade, sendo ambas caracterizadas pela ausência de todo o tipo de violência. A paz está relacionada ao desenvolvimento, aos direitos humanos, à diversidade e à cooperação entre pessoas, grupos ou nações. De acordo com Jares (2002), a mesma pode ser entendida como "um fenômeno amplo e complexo que exige uma compreensão multidimensional" (p.131). Partindo-se do pressuposto de que o conceito de paz adquire diferentes significados nos diferentes contextos socioculturais, somente através da adoção de uma visão ampla é que será possível compreendê-la melhor em seus processos e resultados.

Galtung (1986), um grande estudioso do assunto, propôs o conceito de paz a partir de duas definições: a paz negativa, definida como ausência de violência e organizada a partir de grandes grupos como países, raças e etnias; e a paz positiva, definida a partir da cooperação e integração entre esses grandes grupos. O autor argumenta que o conceito de paz positiva deve ser explorado, pois é ele que movimenta as pessoas em seus contextos. Guimarães (2005) concorda com essa visão e propõe uma noção de paz muito mais processual, multicultural e dialógica do que um estado de espírito. Afirma que a mesma deve ser pautada em ações e relações concretas e não apenas em ideais.

Balestreri (2003) também reflete que o tema da paz está longe de ser tão somente um macro tema sócio-político-econômico, o qual mira a superação dos grandes conflitos históricos de massa: ele carrega uma gravidade individual, pessoal, nominal, irrecusável e intransferível. Essa é, segundo o autor, uma reflexão feliz, mas, ao mesmo tempo, perturbadora. "Feliz porque, como toda reflexão, pode apontar alternativas, e perturbadora, porque o mundo não vivencia, com real determinação, uma Cultura de Paz" (p.198).

O interesse mundial pelo tema fez a Organização das Nações Unidas declarar o ano 2000 como "Ano Internacional por uma Cultura de Paz", promovendo uma mobilização mundial em torno do assunto (Organização das Nações Unidas, 2000). O manifesto elaborado por essa mesma organização definiu Cultura de Paz como um conjunto de valores, atitudes, tradições, comportamentos e estilos de vida de pessoas, grupos e nações baseados no respeito pleno à vida e na promoção dos direitos humanos e das liberdades fundamentais, na prática da não violência por meio da educação, do diálogo e da cooperação, podendo ser uma estratégia política para a transformação da realidade social. O referido documento afirma que é da responsabilidade de cada ser humano traduzir valores, atitudes e padrões de comportamento que inspirem a Cultura de Paz na vida cotidiana, no contexto da família, do trabalho, do bairro, cidade ou região, tornando-se um propagador da tolerância, da solidariedade e da mediação.

A Cultura de Paz constitui-se, assim, em processo dinâmico que ocorre de forma individual e coletiva, buscando transformar as mais diversas 
sociedades. De acordo com a Psicologia Cultural, o contexto cultural que valoriza a paz de forma concreta tende a gerar pessoas a ela comprometidas, e vice-versa (Milani \& Branco, 2004). Isso porque o conceito de paz não pode ser visto apenas do ponto de vista teórico ou ideal, mas analisado em termos das práticas culturais concretas para a resolução de problemas.

Em resumo, a Cultura de Paz está intrinsecamente relacionada à prevenção e à resolução não violenta dos conflitos. É uma cultura baseada na tolerância, na solidariedade e no compartilhamento cotidianos; uma cultura que respeita os direitos individuais e o princípio do pluralismo, assegurando e sustentando a liberdade de opinião. Ela se empenha em prevenir conflitos resolvendo-os em suas fontes ou origens. Está, assim, diretamente relacionada com a cidadania (Moreira \& Branco, 2012).

Os conflitos, por sua vez, a princípio tidos somente como negativos, ganharam definições e significados diferenciados nas pesquisas sobre desenvolvimento humano. Jares (2002) o define como "um tipo de situação na qual as pessoas ou os grupos sociais buscam ou percebem metas opostas, afirmam valores antagônicos ou têm interesses divergentes, ou seja, é um fenômeno de incompatibilidade" (p.135). Ressalta que a paz nega a violência, porém não nega os conflitos, pois estes fazem parte da vida.

É bem verdade que muitos conflitos foram e ainda são geradores de violência, o que pode dar origem a grandes tragédias, seja na família ou guerra entre países, como tem ocorrido no Oriente Médio. Isso ocorre porque as pessoas têm dificuldade em internalizar e vivenciar a paz como um valor social importante, o que se verifica desde o nível micro - como nas famílias, escolas - até o macro -, como o urbano, regional, nacional e mesmo internacional.

O conflito é algo inerente ao ser humano. Onde existe relação necessariamente haverá conflito. E estes são de grande importância na própria promoção do desenvolvimento humano (Valsiner \& Cairns, 1992), particularmente aqueles considerados pelos referidos autores como tipicamente construtivos, ou seja, os que se caracterizam por negociações bem sucedidas. Assim, o processo de construção da paz inclui a presença de conflitos, mas a grande diferença está em que contextos específicos estes surgem, e como são resolvidos. Dessa forma, torna-se possível promover processos construtivos que irão, pouco a pouco, gerando uma Cultura de Paz da sociedade como um todo.

Mas e a questão da violência? Ela está frequentemente associada à agressão e ultrapassa o limite estabelecido pelo respeito e consideração pelos outros, seja no nível pessoal ou institucional. A violência impede ou dificulta o desenvolvimento individual e social e, ao se tornar uma prática cultural corriqueira, acaba por gerar significados no contexto sociocultural que certamente dificultam a promoção da paz e a melhoria na qualidade de vida das pessoas.

Segundo o Ministério da Saúde (Brasil, 2009), a violência é um problema social de grande dimensão que afeta toda a sociedade, atingindo crianças, adolescentes, homens e mulheres. É responsável, no mundo inteiro, por adoecimentos, perdas e mortes e se manifesta através de ações realizadas por indivíduos, grupos, classes e nações, provocando danos físicos, emocionais e/ou espirituais a si próprios ou aos outros.

Galtung (2006) distingue dois tipos de violência: física e psicológica. A primeira pode ser direta, quando o uso da força provoca danos corporais, ou indireta, quando há exploração de qualquer ordem. A segunda, a violência simbólica, também pode ser direta, de forma verbal ou não verbal, ou indireta, quando há a destruição de bens culturais ou símbolos valorizados por pessoas ou grupos específicos.

Nos estudos de Minayo e Souza (1999) sobre o assunto, os autores afirmam que se trata de um complexo e dinâmico fenômeno biopsicossocial, cujo espaço de criação e desenvolvimento é a vida em sociedade. Na medida em que a violência é definida como uma relação humana, pode-se compreendê-la também como um comportamento culturalmente aprendido, o qual passa a fazer parte dos padrões intrapsíquicos. Portanto, é um fenômeno que pode ser desconstruído (Minayo \& Souza, 1999). 
Na Psicologia do Desenvolvimento, é através do processo de socialização que a cultura transmite seus valores, crenças e normas para o ser humano. Assim, é por meio da socialização que valores e práticas de violência e paz são co-construídos. A socialização é um processo dinâmico que provoca condições diversas para o desenvolvimento. Estudos mostram, por exemplo, que a prática de ajudar pessoas é mais importante do que as regras morais para o desenvolvimento de comportamentos pró-sociais (Staub, 2003). Os valores sociais representam, de acordo com o autor, parte essencial do sistema complexo da motivação social, pois direcionam, transformam e promovem comportamentos e interações específicos ao longo do processo de socialização. E isso pode ter um impacto no incentivo a comportamentos pró-sociais e de cooperação, essenciais à construção de uma Cultura de Paz.

\section{A polícia militar como instituição social}

Segundo a Constituição Federal, artigo 144, $\S 5^{\circ}$ e $\S 6^{\circ}$ (Brasil, 1988), as Polícias Militares são forças auxiliares reservas do Exército, subordinadas aos governadores dos estados. Busca estabelecer e preservar a paz social nos âmbitos público e privado, prestando um serviço eficaz e eficiente aos cidadãos. A Polícia Militar tem como missão o policiamento ostensivo, preventivo e repressivo, a preservação da ordem pública, a incolumidade das pessoas e do patrimônio, a manutenção da tranquilidade pública e da paz social. Dessa forma, observa-se que promover a paz é parte integrante da missão dessa instituição.

Os valores da Polícia Militar do Estado estão estabelecidos no Artigo $6^{\circ}$ de seu Código de Ética estabelecido pelo Decreto $n^{\circ} 1642$, de 28 de agosto de 1990. São eles: patriotismo, civismo, hierarquia, disciplina, profissionalismo, lealdade, constância, espírito de corpo, honra, dignidade, honestidade e coragem (Brasil, 1990). Estes devem, assim, ser amplamente difundidos nos cursos de formação e durante toda a carreira do policial militar. São valores institucionais que, com o tempo, devem se tornar individuais no exercício da profissão.
A Polícia Militar, enquanto instituição social, tem uma dupla responsabilidade na construção de uma Cultura de Paz: uma com seus membros, com suas histórias individuais e familiares, e outra com a sociedade de forma geral, que é atendida pelos policiais militares e que com eles interage.

O trabalho atual da Polícia Militar do Estado onde foi feita a pesquisa é orientado por uma administração cujo objetivo é melhorar o atendimento à sociedade, ao mesmo tempo em que busca o desenvolvimento e a motivação de seus integrantes. Assim, os policiais militares devem estar preparados para lidar com os problemas cotidianos dos cidadãos comuns, atuando como mediadores de conflitos e restringindo a coerção a casos extremamente necessários.

Dessa maneira, considera-se que a construção de uma Cultura de Paz é, antes de tudo, um grande desafio a ser vencido por todos, nas diferentes culturas, e tem por meta principal promover o respeito às diversidades e melhorar a qualidade de vida no mundo. Sendo a investigação e a realização de trabalhos científicos no contexto da Polícia Militar ainda bastante reduzidas, a presente pesquisa se dispõe a contribuir nessa direção. O estudo buscou, adotando uma metodologia qualitativa, investigar e compreender as convicções, crenças e valores de policiais militares relacionados à construção de uma Cultura de Paz. Acredita-se que esses profissionais podem desenvolver valores e competências que os levem a ser promotores dessa cultura nas diversas funções as quais desempenham dentro e fora da corporação.

\section{Método}

\section{Participantes}

Participaram do estudo seis policiais militares de um estado brasileiro, sendo quatro homens e duas mulheres. As informações relativas aos participantes da pesquisa estão na Tabela 1 e foram obtidas durante a entrevista individual. Foram utilizados nomes fictícios para garantir o sigilo e o anonimato total dos participantes. 
Tabela 1

Informações sobre os Policiais Militares participantes da pesquisa. Palmas (TO), 2010

\begin{tabular}{lllll}
\hline Nome Fictício & Idade (anos) & Tempo de PM (anos) & Filhos e idade & Escolaridade \\
\hline Sara & 28 & 5 & $1(8$ anos $)$ & Superior completo \\
Pedro & 33 & 11 & $2(12,10$ anos $)$ & Superior completo \\
Felipe & 44 & 24 & $5(18,18,17,14,10$ anos $)$ & Superior completo \\
Lucas & 38 & 18 & $3(16,14,13$ anos $)$ & Ensino Médio \\
Verônica & 25 & 06 & $1(2$ anos $)$ & Superior completo \\
Marcos & 36 & 10 & $1(6$ anos $)$ & Ensino Médio \\
\hline
\end{tabular}

Nota: PM: Polícia Militar.

\section{Instrumentos}

Foram utilizados como instrumentos de investigação: roteiros de entrevistas semiestruturadas individuais, elaborados para a pesquisa, e gravador digital.

\section{Procedimentos}

O projeto foi submetido e aprovado pelo Comitê de Ética e Pesquisa da Universidade de Brasília, sob registro de número 023/10 em 11/06/2010. Com a devida aprovação, iniciou-se o contato com o Comando Geral da Polícia Militar do Estado pesquisado, sendo solicitada e concedida autorização para realização do estudo. As entrevistas foram realizadas após os sujeitos assinarem o Termo de Consentimento Livre e Esclarecido.

\section{Resultados e Discussão}

A partir dos indicadores empíricos obtidos com as análises das entrevistas semiestruturadas, estabeleceu-se algumas categorias significativas para a discussão.

\section{A Polícia Militar como instituição}

Os participantes percebem a Polícia Militar como uma instituição forte, com pontos positivos e negativos, da qual a maioria gosta muito de fazer parte. Cada um, com suas motivações pessoais, afirma que muitas coisas vêm mudando para melhor com o tempo, mas outras ainda precisam ser modi- ficadas. Em termos gerais, como fatores negativos para a construção de uma Cultura de Paz, os participantes dizem sentir falta de maior integração entre os membros da instituição, além de se referirem à: divisão de classes, busca individualista por interesses próprios, ingerência política e desigualdade de oportunidades.

Todos os entrevistados afirmaram que a instituição melhorou muito com o tempo e citaram o ingresso dos profissionais de saúde no ano de 2005 como um fator causador dessa melhora. Felipe disse que "Naquele tempo [passado] as coisas eram diferentes, um subordinado não tinha direito a nada e se alguém hierarquicamente superior não gostasse da pessoa, Ihe aplicava punições sem nenhuma justificativa plausível". Na visão dos participantes a instituição está em franco desenvolvimento, tanto em termos de questões legais (regulamentos internos) quanto de humanização, valorização profissional, promoção da saúde e apoio à família.

Quando foram perguntados se seriam voluntários para um programa de construção da Cultura de Paz na instituição, todos responderam "Sim", sem hesitar; mas quando a pergunta "Como você ajudaria?" foi feita nenhum participante soube responder. Alguns, inclusive, excluíram sua participação utilizando explicações desconexas como " $A$ Segurança Pública precisa dar sensação de segurança para as pessoas..." (Pedro) e, também, "Eu acredito que alguém deveria comprar a responsabilidade, pegar a responsabilidade pra si. Porque fica um esperando que o outro faça..." (Marcos). Ou seja, parece que não se reconhecem como agentes de promoção de uma Cultura de Paz em potencial, tanto dentro como fora da Polícia Militar. Esses 
posicionamentos limitam suas ações a respeito da paz como um processo em contínua construção, principalmente com novas iniciativas, atitudes diferenciadas e ações concretas.

\section{Conceito de paz e Cultura de Paz}

Observou-se que o termo Cultura de Paz causou estranheza em cinco participantes, os quais não souberam defini-lo ou se atrapalharam em suas definições, sendo que apenas Verônica de fato conhecia o termo. Precisaram da insistência da pesquisadora para pensarem sobre o tema, o que demonstra total desconhecimento do significado do conceito. Apesar dessa dificuldade inicial, eles se esforçaram diante do questionamento, fazendo ligações com as temáticas abordadas ao longo da entrevista, o que caracteriza o processo de co-construção que ocorre no contexto de entrevistas semiestruturadas.

O conceito de paz recorrente entre os participantes refere-se à mesma como "estado de espírito, algo interior, subjetivo". Pedro utilizou a expressão "sensação de estar em paz", sugerindo que a paz é uma sensação ou um sentimento. Nota-se que esses pontos revelam crenças permeadas pela cultura da sociedade atual, na qual a paz é vista como algo subjetivo, ligado muito mais à noção de harmonia interior e espiritualidade do que à paz social. Esses indicadores são compatíveis com aqueles encontrados por Manzini, Leite, Cardoso, Gonzáles e Branco (2012) entre professoras de escolas públicas do Distrito Federal, as quais igualmente definiram paz como algo subjetivo (serenidade, tranquilidade), não fazendo referência às relações humanas. Isso é bastante surpreendente, tanto entre professoras como entre policiais militares, uma vez que ambos estão diariamente diante de situações de violência interpessoal. O fato das duas categorias não serem capazes de relacionar Cultura de Paz com prevenção da violência é um dado importante que merece ser analisado mais profundamente.

A paz, de acordo com os participantes, foi também relacionada com boas condições financeiras, sendo dito que nos locais mais pobres da cidade as pessoas têm mais dificuldades em ter paz por falta de "condições". Como pode ser observado na fala de Felipe: "Sempre eu priorizei os meus patrulhamentos, a minha presença onde o Estado é mais ausente, porque onde o Estado é mais ausente as pessoas são mais carentes e a criminalidade acontece com mais frequência, porque o pessoal é totalmente desassistido".

Como se pode perceber, o conceito de paz entre os participantes está muito distante do proposto por pesquisadores do tema, como Balestreri (2003), De Rivera (2009), Dusi (2006), e Jares (2002). Esses autores afirmam que o conceito se refere a estruturas e relações sociais caracterizadas não só pela ausência da violência, mas pela presença de justiça, igualdade, respeito, liberdade e valores humanistas. Ou seja, é um processo em contínuo desenvolvimento que se constrói ao invés de se adquirir, e que depende de ações concretas realizadas cotidianamente. Verônica faz uma reflexão interessante sobre o tema:

“... . Em uma atividade de rua buscar uma cultura de paz, é justamente isso, fazer meu trabalho sem ter que exacerbar, sem ter que extrapolar os limites legais, principalmente isso. E é algo que a gente tenta alcançar, mas às vezes a nossa atividade é um pouco difícil, apesar da gente estar ali, promover a paz, mas a gente acaba tendo que usar a força e é um pouco contraditório... . Eu acho contraditório porque a gente não utiliza sempre de meios pacíficos pra poder conter um certo conflito e nem tem como, né? ... . Apesar de que a gente tá querendo resolver aquilo ali e trazer paz novamente pro local ..." .

A participante reconhece que o exagero da atividade policial não contribui para a Cultura de Paz, mas, dependendo da situação, o uso da força é essencial para restabelecer essa condição. A participante mostra-se consciente da contradição muitas vezes presente no trabalho do policial. Essa consciência é certamente fundamental para a busca de novas formas de intervir, novas estratégias a adotar. A participante, assim, consegue perceber que ser um agente da paz é essencial para o sucesso da missão do policial militar, devendo ele ter condições 
de avaliar e dominar suas ações a cada momento e utilizar a melhor opção para restabelecer a paz na situação ou contexto específico.

Na visão de Milani (2003), construir uma Cultura de Paz é promover as transformações necessárias e indispensáveis para que a paz seja o princípio governante e orientador de todas as relações humanas e sociais. Assim sendo, a mesma é construída por meio de ações e interações cotidianas que compõem um movimento individual e coletivo, o qual se transforma paulatinamente em uma Cultura de Paz (Moreira \& Branco, 2012).

\section{Conceito de conflito}

De uma forma geral, os participantes entendem que conflito é uma divergência de ideias ou interesses, onde um lado não aceita a vontade ou opinião do outro. Todos eles só o compreendem como sendo algo negativo, aproximando-o muito do conceito de violência. Explorando o assunto, alguns concluem que existem conflitos positivos ou importantes, porém, perdem-se na exemplificação e acabam reafirmando que os mesmos positivos não existem.

Essa dificuldade para perceber o conflito como sendo positivo ou importante está diretamente relacionada com a dificuldade de pensar e vislumbrar uma Cultura de Paz a partir de ações concretas por eles promovidas ou mediadas. Se o conflito é sempre negativo, então deve ser eliminado e, assim, tem-se a paz. No entanto, os estudiosos sobre a paz afirmam que o conflito é algo inerente ao ser humano e à sociedade, ambos em desenvolvimento. Onde existe relação ele, necessariamente, estará presente (Jares, 2002). Os conflitos podem ser de grande importância para a própria promoção do desenvolvimento humano, particularmente aqueles que os especialistas consideram como tipicamente construtivos (Valsiner \& Cairns, 1992). Assim, constituem algo essencial para o aprimoramento das relações entre os seres humanos e para a construção de uma sociedade mais justa, igualitária, democrática e plural.

Portanto, há uma necessidade real de con560 flitos construtivos para gerar desenvolvimento nas pessoas, instituições e sociedades. É da negociação e da mediação pacífica destes que novas alternativas de resolução de problemas emergem e novas perspectivas podem se abrir (Cappi, 2003; Senna, 2007). Sendo assim, a capacidade de analisar cada conflito em particular e saber agir no sentido de sua resolução construtiva é fundamental na atuação de policiais militares.

\section{A Cultura de Paz na comunidade, na escola e na família}

Ao abordar essa temática nas entrevistas percebeu-se que todos os participantes consideram necessária e positiva a participação da comunidade em programas que visem uma Cultura de Paz. Certamente influenciados pela filosofia da Polícia Comunitária, a qual vem sendo amplamente desenvolvida no Estado pesquisado, visualizam bons frutos a partir da parceria entre polícia e comunidade. Felipe afirma que "A polícia tem que buscar a confiança da comunidade pra ter ela do lado". O mesmo ocorre em relação às escolas devido ao sucesso do Programa Educacional de Resistência às Drogas (PROERD) junto às crianças e, mais recentemente, aos pais. Lucas reforça o sucesso do programa: " $A$ polícia tem um projeto aí que... já desenvolve, um projeto muito importante, muito bonito quando se trata de prevenir a situação do jovem, das crianças, né? Nessa cultura contra as drogas [PROERD], e... já faz um trabalho muito bonito".

No tocante às famílias, todos acham importante difundir a Cultura de Paz principalmente para os filhos, mas ninguém adota uma estratégia ou tem alguma forma mais clara e objetiva de como promovê-la. Na realidade, nenhum dos participantes, aparentemente, pensou a respeito do assunto ou mesmo despertou para a importância dessa reflexão antes. Conforme mencionado anteriormente, de acordo com a perspectiva sociocultural construtivista do desenvolvimento, o contexto sociocultural em que a pessoa está inserida é fundamental na construção de conceitos, valores e padrões de interação (Rogoff, 2005; Valsiner, 2007, 2012). Isso pode gerar sujeitos agressivos ou pacíficos, dependendo da prevalência de práticas violentas ou cooperativas entre as pessoas. 


\section{Pessoas mais velhas não mudam}

De uma forma geral, todos os entrevistados relataram que é mais fácil construir uma Cultura de Paz com os novos integrantes da instituição, porque os "antigões" não mudam, são mais "truculentos", aprenderam de outra forma e agora não conseguem mudar suas ações. Marcos fortalece essa ideia:

"... . Na instituição sim, principalmente com os policias mais, mais jovens. Os mais antigos, aquela velha história do papagaio né? É difícil. São, são mais... geralmente eles são mais assim, aquele pessoal carrancudo, aquele pessoal que não, ta difícil colocar no policial militar... . É, é, na mente deles, não a polícia não foi feita pra trabalhar com a comunidade, com respeito, aquela coisa toda. Os mais jovens não, já, já tão trabalhando em cima disso aí...".

A Psicologia do Desenvolvimento não concorda com essa visão, mas entende que os valores e hábitos de longa data realmente representam obstáculos a serem vencidos. Mudar no trabalho e construir toda uma nova identidade é um desafio de co-construção do ser humano e da Polícia Militar. Existe a ideia recorrente de que na escola é mais fácil se trabalhar. Pedro afirma "mudando uma cabeça hoje... na fase que ainda é possível mudar, quando se tá novo... vai formar opiniões diferentes lá na frente". De fato, os primeiros anos são particularmente sensíveis no que diz respeito à internalização de crenças e valores, mas isso não significa que transformá-los na vida adulta seja impossível. Sara diz que "se a pessoa é nova é fácil mudar, mas se já é mais velha fica difícil". No entanto, de acordo com a Psicologia Científica, sempre será possível promover mudanças ou o desenvolvimento humano (Valsiner, 2012).

\section{O policial militar como modelo social}

Um ponto interessante nesta discussão refere-se ao policial militar como modelo social, uma vez que seu trabalho o coloca diretamente em contato com a sociedade, sendo o único representante do Estado 24 horas por dia nas ruas. Sara fez a seguinte reflexão: "Se a Polícia Militar quiser trabalhar isso na comunidade, eles têm que ver a Polícia Militar como exemplo... . Aí, se eles começarem a perceber isso na polícia, começarem a confiar mais, aí eu acredito que seja possivel". Nota-se que ela tem consciência de que esse profissional deve ser um modelo social e precisa modificar sua conduta pessoal para transformar-se em um promotor da paz. Felipe afirma que

\begin{abstract}
A primeira coisa que você precisa é buscar a confiança da comunidade, a comunidade precisa acreditar na Polícia Militar... . Porque a polícia ela tem 'a faca e o queijo na mão', porque quando a pessoa tá nos momentos difíceis ela é a primeira que chega. Então ela tem a oportunidade de chegar e prestar um serviço bom.
\end{abstract}

Ele também reforça a ideia de que a Polícia Militar é uma referência para a sociedade e, se ela for bem treinada e trabalhar corretamente, poderá obter bons resultados como modelo de ação para a paz. P. L. Berger e Berger (1994) apontam algumas características fundamentais para uma instituição, citando, entre elas, a autoridade moral, a qual Ihe dá legitimidade. A instituição precisa conquistar o respeito social, pois este Ihe ajuda a construir valores, colaborando substancialmente para mudanças na cultura. Nesse sentido, a Polícia Militar poderá contribuir de forma incisiva na construção de uma Cultura de Paz na sociedade.

\section{Expectativas para construir uma Cultura de Paz na Polícia Militar}

Ao final das entrevistas, as questões foram direcionadas para a possibilidade de se construir uma Cultura de Paz na Polícia Militar, buscando sugestões e contribuições pessoais. Todos foram favoráveis e disseram que seriam voluntários para um programa como esse na instituição. Lucas afirma: "Eu acredito que eu já tenho uma experiência de vida bem grande dentro da polícia, eu acho que eu teria condições de ajudar com as minhas ideias, com minha força de vontade, eu já ajudei já muitos colegas". Mesmo com dificuldades de conceituar, 
relacionar e refletir sobre o tema, ele acredita poder ajudar com sua experiência e vivência na carreira através da cooperação. Esta é uma forma de trabalho onde todos se beneficiam e se desenvolvem mutuamente (Palmieri \& Branco, 2004). Além disso, estudos mostram que a prática de ajudar pessoas é mais importante do que as regras morais para o desenvolvimento de comportamentos pró-sociais (Staub, 2003).

Marcos demonstra empolgação e otimismo: "Apesar da dificuldade, é viável, é necessário e é possivel. A dificuldade tem, mas a gente consegue vencer, como já vencemos tantas". Ele também relaciona a Cultura de Paz com uma mudança estrutural, o que de fato acontece quando paradigmas são quebrados e valores transformados. Como afirma Rogoff (2005), a cultura assume papel constitutivo fundamental no desenvolvimento humano através das experiências cotidianas de participação nas práticas socioculturais do grupo, isto é, através das interações sociais.

Verônica também afirma que "Muitos pensam que é mais uma frescura que quer implantar, mas não é. Isso traria muitos benefícios pra tropa como um todo e também pra instituição...". Ela projeta os benefícios de um programa de Cultura de Paz para a instituição, ampliando sua visão do tema: a paz é reconhecida não apenas como a ausência de conflitos, mas como um processo de transformação, dinâmico e participativo em que se promove o diálogo e a resolução cooperativa de conflitos (Dusi, 2006).

Tudo indica que a falta de análise de fenômenos sociais complexos, como violência e construção da paz, deriva do poderoso viés individualista de nossa sociedade. Disso decorre a grande dificuldade dos profissionais em enxergar a relação entre violência e paz social. Assim como outros autores os quais analisam a questão (Branco \& Oliveira, 2012; Jares, 2002; Senna, 2007), Guimarães (2005) entende que é necessária uma concepção de paz como uma questão de qualidade de vida, no que diz respeito ao convívio social, do que algo abstrato e etéreo.

Observou-se que a visão de paz no sentido mais preventivo é algo distante do pensamento dos 562 participantes, pois o problema só incomoda quando afeta diretamente a pessoa ou sua família. Não é costume pensar no fenômeno como um todo. Isso ocorre somente quando existe alguma motivação ou interesse associados a situações particulares, sendo que o mesmo ocorre no caso de policiais militares.

\section{Considerações Finais}

Construir uma Cultura de Paz é algo que demanda a transformação efetiva de crenças, valores, comportamentos, interações e relações entre as pessoas. Implica renunciar hábitos antigos e criar novos objetivos e estratégias, modificar estruturas ineficientes, enfim, abandonar zonas de comodismo. A paz como um processo contínuo e dinâmico movimenta a vida em prol de algo melhor, individual e coletivo, de forma que todos possam ser beneficiados.

Nesta pesquisa buscou-se estudar, analisar e compreender os múltiplos componentes que envolvem a construção e promoção da Cultura de Paz na visão de policiais militares. Procurou-se enfatizar, com o apoio da abordagem sociocultural construtivista, que as práticas culturais vigentes em determinado contexto, como o da Polícia Militar, necessitam de reflexão constante e podem ser remodeladas a fim de promover valores e comportamentos mais pró-ativos e cooperativos.

Deve-se considerar que a instituição supracitada cuida da segurança da sociedade, ao mesmo tempo em que forma profissionais, e estes, por sua vez, constróem famílias e interagem com muitas pessoas. Ao dar segurança aos cidadãos, defrontam-se com situações em que o desempenho do seu papel profissional os leva a conviver com a insegurança e a violência. O alto grau de tensão a que são submetidos os expõe constantemente aos limites institucionais e aos da própria condição humana, do convívio com a violência e agressão, da coisificação do outro e do dilema dominação-submissão em situações de risco e perigo. No exercício de sua profissão, vivenciam cotidianamente esse paradoxo e caminham constantemente na interface entre a paz e a violência.

Assim sendo, afirma-se que os policiais militares tem uma grande responsabilidade e impor- 
tância na construção da Cultura de Paz, devendo desenvolver essa consciência, e as habilidades e competências necessárias para serem efetivos agentes multiplicadores da paz. Para tanto, sugere-se que a Polícia Militar estude e busque desenvolver programas com esse objetivo, fortalecendo seu elo com a comunidade e cumprindo de forma mais profunda e efetiva seu papel social.

\section{Colaboradores}

Todos os autores contribuíram na concepção e desenho do estudo, análise de dados e redação final.

\section{Referências}

Balestreri, R. (2003). Consciência moral e construção da paz. In R. Balestreri (Org.), Na inquietude da paz. Passo Fundo: Ceduc.

Berger, P. L., \& Berger, B. (1994). O que é uma instituição social? In M. Foracchi \& J. Martins. Sociologia e sociedade (pp.238-256). Rio de Janeiro: LTC.

Branco, A. U., \& Oliveira, M. C. L. (2012). Diversidade e cultura da paz na escola. Porto Alegre: Mediação.

Branco, A. U. (2006). Crenças e práticas culturais: co-construção e ontogênese de valores sociais. Revista Pro-Posições, 17(2), 139-155.

Brasil. Governo do Estado de Tocantins (1990). Decreto $\mathrm{n}^{\circ} 1.642$, de 28 de agosto de 1990. Aprova o Regulamento Disciplinar da Polícia Militar do Estado. Diário Oficial do Estado, n 178.

Brasil. Ministério da Saúde. (2009). Por uma cultura da paz, a promoção da saúde e prevenção da violência. Brasília: Autor. (Série F: Comunicação e Educação em Saúde).

Brasil. Presidência da República. (1988). Constituição da República Federativa do Brasil. Título V - Da Defesa do Estado e Das Instituições Democráticas. Capítulo III - Da Segurança Pública, art. 144, § $5^{\circ}$ e §6. Diário Oficial da União, out.1998.

Cappi, R. (2003). Paz nas escolas: o papel da polícia. In R. Balestreri (Org.), Na inquietude da paz. Passo Fundo: Ceduc.

Cole, M. (1992). Culture in development. In M. H. Bornstein \& M. E. Lamb (Orgs.), Developmental Psychology: An advanced textbook (pp.731-788). Hillsdale: Lawrence Erlbaum Associates.

De Rivera, J. (2009). Assessing the peacefulness of culture. In J. De Rivera, Handbook on building cultures of peace (pp.89-103). Worcester: Springer.

Dusi, M. M. (2006). A construção da cultura de paz no contexto da instituição escolar (Dissertação de mestrado não-publicada). Universidade de Brasília.

Galtung, J. (1986). Sobre la paz: violencia, paz y investigación sobre la paz. Barcelona: Fontamara.
Galtung, J. (2006). Transcender e transformar: uma introdução ao trabalho de conflitos. São Paulo: Palas Athenas.

Guimarães, M. R. (2005). Educação para a paz: sentidos e dilemas. Caxias do Sul: Educs.

Jares, X. R. (2002). Educação para a paz: sua teoria e sua prática. Porto Alegre: Artmed.

Manzini, R. G. P., Leite, L. M. N., Cardoso, B. C. C., González, A. M. B., \& Branco, A. M. C. U. A. (2012). A questão do bullying: prevenção da violência e promoção da cultura da paz. In A. M. C. U. A. Branco \& M. C. S. L. de Oliveira (Orgs.), Diversidade e cultura da paz na escola (pp.311-28). Porto Alegre: Mediação.

Milani, F., \& Branco, A. (2004). Assessing Brazil's culture of peace and conflict. Peace and Conflict, 10(2), 161-174.

Milani, F. M. (2003). Cultura de paz x violência. In F. M. Milani \& R. C. Jesus (Orgs.), Cultura de paz: estratégias, mapas e bússolas. Salvador: Inpaz.

Minayo, M. C. S., \& Souza, E. R. (1999). É possível prevenir a violência? Reflexões a partir do campo da saúde pública. Ciência \& Saúde Coletiva, 4(1), 7-32.

Moreira, L. S., \& Branco, A. U. (2012). Cultura de paz, moralidade e virtudes cívicas: contribuições da Psicologia Cultural. Psicologia Argumento, 30(68), 161-170.

Organização das Nações Unidas. (2000). Manifesto 2000. Recuperado em setembro 15, 2010, de http//:www. onu.org.

Palmieri, M. W. A., \& Branco, A. U. (2004). Cooperação, competição e individualismo em uma perspectiva sociocultural construtivista. Psicologia: Reflexão e Crítica, 17(2), 189-198.

Rogoff, B. (2005). A natureza cultural do desenvolvimento humano. Porto Alegre: Artmed.

Senna, S. F. (2007). Protagonismo infantil e promoção da cultura de paz: um estudo sociocultural construtivista (Tese de doutorado não-publicada). Universidade de Braślia.

Staub, E. (2003). The Psychology of good and evil: Why children, adults, and other groups help and harm others. New York: Cambridge University Press.

Unesco. (1991). Ato constitutivo promulgado pelo Decreto $n^{\circ}$ 362. Brasília: República Federativa do Brasil.

Valsiner, J., \& Cairns, R. (1992). Theoretical perspectives on conflict and development. In C. V. Shantz, \& W. W. Hartup (Orgs.), Conflict in child and adolescent development (pp.15-35). Cambridge: Cambridge University.

Valsiner, J. (2007). Culture in minds and societies: Foundations of cultural psychology. New York: Delhi Sage.

Valsiner, J. (2012). Fundamentos de Psicologia Cultural: mundos da mente, mundos da vida. Porto Alegre: Artmed.

Vygotsky, L. (1989). Pensamento e linguagem. São Paulo: Martins Fontes.

Recebido: abril 29, 2014

Versão final: dezembro 15, 2014

Aprovado: abril 7, 2015 
